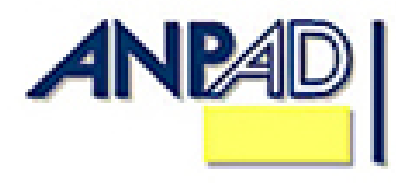

Available online at http://www.anpad.org.br/bar

BAR, Curitiba, v. 8. , n. 1, art. 1, pp. 1-20, Jan./Mar. 2011

\title{
The Smoothing Hypothesis, Stock Returns and Risk in Brazil
}

\author{
Antonio Lopo Martinez * \\ E-mail address: lopo@fucape.br \\ FUCAPE Business School \\ Vitória, ES, Brazil.
}

Miguel Angel Rivera Castro

E-mail address: marc@ufba.br Universidade Federal da Bahia - UFBA

Salvador, BA, Brazil.

* Corresponding author: Antonio Lopo Martinez

Avenida Princesa Isabel, 542/1201, Salvador, BA, 40130-030, Brazil.

Copyright (C) 2011 Brazilian Administration Review. All rights reserved, including rights for translation. Parts of this work may be quoted without prior knowledge on the condition that the source is identified. 


\begin{abstract}
Income smoothing is defined as the deliberate normalization of income in order to reach a desired trend. If the smoothing causes more information to be reflected in the stock price, it is likely to improve the allocation of resources and can be a critical factor in investment decisions. This study aims to build metrics to determine the degree of smoothing in Brazilian public companies, to classify them as smoothing and non-smoothing companies and additionally to present evidence on the long-term relationship between the smoothing hypothesis and stock return and risk. Using the Economatica and CVM databases, this study focuses on 145 companies in the period 1998-2007. We find that Brazilian smoothers have a smaller degree of systemic risk than non-smoothers. In average terms, the beta of smoothers is significantly lower than non-smoothers. Regarding return, we find that the abnormal annualized returns of smoothers are significantly higher. We confirm differences in the groups by nonparametric and parametric tests in cross section or as time series, indicating that there is a statistically significant difference in performance in the Brazilian market between firms that do and do not engage in smoothing.
\end{abstract}

Key words: income smoothing; abnormal return; risk; portfolio selection. 


\section{Introduction}

Earnings management has been the subject of extensive accounting and financial research over the past three decades. A significant portion of this work has examined income smoothing, a special case of earnings management. The initial works in the smoothing literature focused on detecting smoothing. The empirical question was whether firms deliberately dampen fluctuations around some expected earnings trend. While the results of early studies were inconclusive, recent evidence has generally supported the hypothesis that many firms appear to smooth income.

Most papers published on the subject focus on analyzing the factors that lead to smoothing or contrast whether or not this phenomenon does indeed exist in different sectors. The international literature, works on the relationship between market returns and the degree of income smoothing in business include those of Michelson, Jordan-Wagner and Wooton (1995, 1999), Booth, Kallunki and Martikainen (1996), Bin, Wan and Kamil (2000), Iñiguez and Poveda (2004), Bao and Bao (2004), Tan and Jamal (2006), Tucker and Zarowin (2006) and Grant, Markarian and Parbonetti (2007), analyzing the American, Finnish, Malay and Spanish markets. Of these, only those of Michelson et al. (1995, 1999) and Iñiguez and Poveda (2004) contain long-term analyses, and the authors come to very different conclusions, working with different methodologies.

In this paper we study the effect of income smoothing on the Brazilian market to verify whether there is an association between the degree of income smoothing and the level of risk and shareholder return. Brazil provides an interesting setting to test the effectiveness of income smoothing with asymmetric information. Is the income smoothing hypothesis really true in the Brazilian market?

This article is organized into thematic sections. After this introduction, the second section presents a brief description of income smoothing and a review of the papers on this issue. In addition it sets out the research design and the analysis of abnormal returns. The fourth section contains the results of the empirical analysis. Finally, the fifth section summarizes the main findings for the Brazilian market.

\section{Theory}

\section{The income smoothing hypothesis}

As far back in the mid-1960s, Gordon (1964) observed that corporate managers may be motivated to smooth income under the assumption that stable income and growth rate will be preferred over higher average income streams with greater variability. More specifically, Gordon theorized income smoothing as follows:

- Proposition 1: The criterion managers use when choosing among accounting principles is maximization of utility or welfare.

- Proposition 2: The utility of managers increases with (a) their job security, (b) the level and growth rate of their income, and (c) the level and growth rate of corporate size.

- Proposition 3: The achievement of the management goals stated in Preposition 2 is dependent in part on stockholders' satisfaction with the corporation's performance; i.e., all things being equal, the happier the stockholders are, the greater the job security, income, etc., of managers.

Proposition 4: Stockholders' satisfaction with a corporation increases with the average rate of growth in its income (or the average rate of return on capital) and the stability of its income. This preposition is a readily verified as Proposition 2 . 
Theorem: Given that the above four proposition are accepted or found to be true, it follows that managers would, within the limits of their power, i.e., the latitude allowed by accounting rules, (a) smooth reported income, and (b) smooth the rate of growth of income. 'Smoothing the rate of growth in income' means if the rate of growth is high, accounting practices that reduce it should be adopted, and vice versa.

The empirical tests of the income smoothing hypothesis are typically tests of a joint hypothesis, that in the absence of manipulation by management, accounting earnings follow a particular process and managers adopt or change accounting procedures to reduce the variance of that process.

In theory, it can be assumed that earnings before manipulation are generated by the following process:

$$
\tilde{\mathrm{A}}_{\mathrm{t}}=\Psi+\delta t+\tilde{\omega}_{\mathrm{t}},
$$

where $\tilde{\mathrm{A}}_{t}$ is the earnings of period $t, \Psi$ and $\delta$ are parameters, $\tilde{\omega}_{t}$ is a random disturbance term, $\mathrm{E}\left(\tilde{\omega}_{t}\right)=0$ and $\sigma_{\mathrm{w}}{ }^{2}$ is constant for all $\mathrm{t}$, and managers are assumed to select an accounting procedure to reduce $\sigma_{\mathrm{w}}{ }^{2}$.

The assumptions of the income smoothing literature have implications for the time series of reported earnings. For example, in the previous case, if true earnings follow the process described by equation (1) and managers smooth by reducing the variance of earnings around the line $\Psi+\delta t$, the reported earnings $\left(\overline{\mathrm{A}}_{\mathrm{t}}\right)$ will also follow a linear process. In fact, the process will be:

$$
\overline{\mathrm{A}}_{\mathrm{t}}=\Psi+\delta t+\breve{\mathrm{U}}_{\mathrm{t}},
$$

where $\breve{U}_{t}$ is a disturbance term. If managers smooth successfully, $\sigma_{v}{ }^{2}<\sigma_{w}{ }^{2}$. Hence, the joint hypothesis (smoothing and equation (1)) can be tested by observing whether the time series of reported earnings do, in fact, follow a process such as equation (2).

\section{The dimension of smoothing}

According to Ronen and Yaari (2007), there are two types of smoothing: real and artificial. Real smoothing involves making production and investment decisions that reduce income variability. In contrast, artificial smoothing is achieved through accounting practices.

Michelson et al. (1995) performed a long-run empirical analysis between smoothing and stock profitability, using U.S. companies' stock information as their sample. They classified the companies as smoothers and non-smoothers based on the sales variation coefficient vs. the earnings variation coefficient. Using geometric series of returns as a basis for calculation, they showed that the nonsmoother sample had larger average income than the smoother sample. However, the monthly average income used in their study was not adjusted for risk or market (normal returns). There also was a difference in size and risk between the two samples: the smoothing group was larger and had a smaller beta than the non-smoothing group, even though there was no statistical evidence to support this outcome.

Booth et al. (1996) studied the Finnish market to see if abnormal return, as derived from earnings disclosures, was different between companies that do and do not show smoothing behavior, based on the variation coefficient method. The results showed that smoothers tended to be bigger than non-smoothers, and the former also had smaller betas than their counterparts. When speaking of abnormal returns, the non-smoothers showed better market performance against variability of income when compared to smoothers.

More recently, Michelson et al. (2001) revisited their study of 1995 to see if the accounting performance measures are related to income smoothing, but this time using abnormal returns. The results of this methodology are based on the accumulation of abnormal returns using arithmetic series. The 
results showed that smoothers have a significantly higher abnormal return than non-smoothers. The smoothers, according to the market value of liquid assets, were bigger than non-smoothers.

Another study that deserves to be mentioned is that of Iñiguez and Poveda (2004) concerning smoothing in the Spanish market. They did this through a long-run study (10 years) of the relationship of income smoothing, risk and abnormal return. Using coefficients of variation, they obtained results showing a behavior pattern of returns and beta related to the degree of smoothing (variation of earning in this study were adjusted discretionarily). Their empirical evidence suggests that smoothers obtain better returns in the capital market than non-smoothers do. In relation to systematic risk, smoothers present less risk. In short, they concluded that the Spanish capital market does not process information on income smoothing efficiently by permitting the reduction of systematic risk of stocks and improving their return through management of earnings.

The relationship between income smoothing and firm value is an interesting subject, on which there have been empirical studies for the American, Finnish and Spanish markets. In addition, there are some sparse studies on the subject that show how the market values and reacts to the practice of income smoothing. In this paper, we add to this literature by analyzing the effects of income smoothing on the Brazilian market.

\section{Research Hypothesis}

\section{Income smoothing, risk and stock return}

The null hypotheses are:

H (01): There is NO linear relationship between income smoothing and systematic risk.

H (02): There is NO linear relationship between income smoothing and a company's abnormal return.

The empirical evidence shows that the level of risk is lower in companies that have smoothing behavior (Chalayer, 1994; Iñiguez \& Poveda, 2004; Lev \& Kunitzky, 1974; Michelson et al., 1995). Furthermore, authors tend to agree that income smoothing reduces the uncertainty associated with future cash flows. This is done by reducing the variation of results due to outside economic conditions. A few past studies have included analysis of how firms' returns are associated with income smoothing, though opinions on the subject are diverse.

On the one hand, there are studies that find evidence that smoothing is more common in companies with smaller returns (Archibald, 1967; Ashari, Koh, Tan, \& Wong, 1994; White, 1970). A possible justification for this is that companies with less income are more inclined to smooth out their results because they can communicate to shareholders a perception of less risk and a more controlled set of income results. On the other hand, Carlson and Bathala (1997) found empirical support for their hypothesis that the more lucrative a company is, the more opportunities managers have to even out the variability of results.

Other works on income smoothing say that smoothing facilitates the evaluation of companies by investors. A justification for this increment in the expected value of companies is that stable results are derived from good management (Bhat, 1996; Chaney \& Lewis, 1995; Ronen \& Sadan, 1981). Based on this, the value of a company should be positively associated with the magnitude of the reduction in variation of its results, through income smoothing. 


\section{Income smoothing and size}

H (03): There is NO linear relationship between income smoothing and the size of a company.

The positive theory of accounting has advanced along with the development of new variables used to understand income smoothing techniques. One of the hypotheses developed by this theory associates income smoothing practices to the political visibility of the company and the political costs derived from this heightened attention. Therefore, companies with heightened political visibility are more inclined to smooth their results because variations in results attract the attention of public policymakers. It is important to note that the bigger the company is, the higher its political costs will likely be. Therefore, bigger companies should be more inclined to use income smoothing because they are more visible socially and under the eye of the government and the general public (Chalayer, 1994; Craig \& Walsh, 1989; Iñiguez \& Poveda, 2004; Michelson et al., 1995, 2000; Moses, 1987).

\section{Explanatory classification variables of income smoothing}

In this section we identify the classification variables that are statistically significant to be capable of implementing income smoothing, using a forward stepwise logistic regression in which the variables are tested one by one. Several studies (Chalayer, 1994; Iñiguez \& Poveda, 2004; Michelson et al., 1995, 2001) have obtained empirical evidence supporting the hypothesis that income smoothing is used to reduce the variability of the results and cash flows as a means of reducing perceived risk of the company (beta). In addition to this, the authors that have written on this topic all agree that income smoothing increases the firm's value (Chalayer, 1994; Chaney \& Lewis, 1995; Trueman \& Titman, 1988).

There are also certain characteristics of economic sectors that affect smoothing, based on the hypothesis of positive accounting theory (PAT), to explain firms' accounting practices and understand income smoothing techniques. This theory, qualified as positive according to Watts and Zimmerman (1986), explains accounting policies by the opportunistic behavior of managers, driven by the goal of maximizing their own earnings.

\section{Methodology}

\section{Sample}

To analyze income smoothing practices in the Brazilian market, we chose a deterministic sample of companies listed on the São Paulo Stock Exchange (Bovespa). It is common practice to engage in smoothing practices in the mid to long term (Chalayer, 1994; Copeland, 1968; Eckel, 1981). Therefore, the sample is composed of companies over a 10-year period (1998 to 2007), considering the following conditions:

. The companies selected all had data available for the whole 10-year period, disclosed in quarterly reports during the whole period.

. The companies that had undergone mergers, acquisitions, alterations in fiscal year or any other significant change were eliminated from the sample.

As a result of these conditions, we obtained a sample of 318 companies from the Economatica database and the reports disclosed to the Brazilian Securities Commission (Comissão de Valores Mobiliários [CVM]). These companies where discriminated based on the smoothing measures of Eckel (1981) and Leuz, Nanda and Wisocky (2003) to give a final sample of 147 companies for the 1998-2007 period, divided in two groups: 64 smoothers and 83 non-smoothers. These companies are the basis for the different analyses. 
The sample is controlled by size and no concentration of large companies was identified. However it should be recognized that the criterion for excluding companies that do not have a history of at least 10 years may create some bias in the sample.

\section{Smoothing criterion of Eckel (1981)}

The method used to determine the presence or absence of income smoothing and the firm value results are based on the coefficient of variation model proposed by Eckel (1981) and used later by Booth et al. (1996), Michelson et al. (1995, 2001), Bin et al. (2000) and Bao and Bao (2004). If net income is related to sales by a linear function, then according to this model variable unitary costs remain constant over time, fixed costs do not decrease and gross revenue cannot be smoothed out. Therefore, the variation coefficient of sales should be smaller than the variation coefficient of net income. If this does not happen, Eckel (1981) showed that the company is artificially smoothing its net income.

\section{$C V \Delta \%$ NetIncome $\leq C V \Delta \%$ Sales $\Rightarrow$ Smoothing}

where:

$\Delta \%$ NetIncome $=$ Annual change in net income

$\Delta \%$ Sales $=$ Annual change in sales revenue

$C V(x)=\sigma(x) / \mu(x)$

where

$\mathrm{CV}(x)=$ Coefficient of variation of a random variable

$\mu(x)=$ The mean of a random variable

$\sigma(x)=$ The standard deviation of a random variables

From this logic, many relevant works have been published in the last 20 years, such as those of Albrecht and Richardson (1990), Ashari et al. (1994), Booth et al. (1996), Michelson et al. (1995, 2001), Bin et al. (2000) and Bao and Bao (2004). These authors all have calculated the measure of smoothing as an index of the fraction between the coefficients of variation [CV]:

$$
I A_{1}=\frac{C V \Delta \% \text { NetIncome }}{C V \Delta \% \text { Sales }}
$$

Based on this, it is assumed that an index lower than 1 in absolute value indicates the presence of income smoothing because the coefficient of variation of net income is smaller than the CV of sales. Eckel (1981) demonstrated that this situation is a result of income smoothing by managers. We modified the model used in this study by using a smoothing index (SI) between 0.90 and 1.10 as the gray area. This procedure is necessary to reduce the classification error, in accordance with the methodology of Chalayer (2004).

$$
0,9 \leq\left[\left|\frac{C V \Delta \% \text { NetIncome }}{C V \Delta \% \text { Sales }}\right|\right] \leq 1,10
$$

$$
\text { Smoothing } \leq \mid \text { Gray Area } \mid \leq \text { Non Smoothing }
$$

In this study we use a selection criterion between smoothers and non-smoothers based on the SI. The result of this SI provides the basis to test the hypothesis that management is motivated to lower the variability of results and cash flow, all with the objective of reducing the firm's perceived risk. 
The criterion of using the SI as a basis to differentiate between smoothers and non-smoothers is based on the following reasons:

1. In the first place, for Bao and Bao (2004), the index considers the aggregated effect of all the accounting variables that smooth net income, describing a behavior pattern of a company in relation to income smoothing. Companies do not usually choose the accounting procedures arbitrarily; they do this considering the overall effect of the result on the market. Because of this, choosing a single variable as the only basis for smoothing could lead to wrong conclusions. This is because the aggregated effect of other variables was not taken into account.

2. Second, according to Albrecht and Richardson (1990), another advantage of this method is that it provides a measure of the variability of the sample and thus permits comparison between different groups. Besides this, it makes it possible to compare data that have different standard deviations and means. These qualities make the SI a practical instrument for selecting groups based on their degree of smoothing. However, Eckel (1981) considered that the main weakness of this method is its failure to recognize firms that have reduced the variability of their net income as smoothers (this reduction in net income should not be greater than their reduction in sales variability).

According to the coefficient of variation method, the more the SI tends to zero, the more smoothed out the firm's earnings are. Generally speaking, the coefficient of variation is calculated from the change $(\Delta)$ of results from one year to another. This assumes a tendency of the results to increase and smooth out (Eckel, 1981).

Furthermore, despite the many procedures managers have to disclose a series of smoothed results, these procedures do not permit perfect income smoothing. Therefore, the coefficient of variation will never be zero, so there is a need to determine the level (arbitrary) at which income smoothing is taking place. There is also a need to introduce a variable for the firm's economic sector: if the CV of the firm is lower than the average $\mathrm{CV}$ of its sector, the firm is classified as an intentional smoother. It is important to remember that the levels set for the CV are arbitrary (Eckel, 1981).

\section{Smoothing criteria of Leuz et al. (2003)}

The criteria explained here are taken from the empirical study by Leuz et al. (2003). Managers can omit changes in economic performance by making real operational decisions or through the use of accounting practices. Smaller values of this criterion show that, ceteris paribus, managers have the power to freely apply income smoothing shown in accounting reports. Operational cash flow is indirectly calculated through lowering accruals to net income. First of all, we apply this criterion on each firm of the sample with estimation in a time series:

Net Income = Operating Cash Flow $(O C F)+$ Accruals

The second criterion to measure the degree of smoothing in Brazilian companies is:

$$
I A_{2}=\frac{\sigma\left(\text { Operating__ncome }_{i t}\right)}{\sigma\left(\text { Operating_CashFlow }_{i t}\right)}
$$

Managers have the discretion to mask economic changes in the cash flow. For instance, they can move up recognition of future earnings or delay recognizing current costs to mask poor economic performance, or vice versa to dampen extremely positive results (Leuz et al., 2003). Besides this, managers usually do not show perfect performance because they create reserves for the future. These accruals are used to amortize changes in cash flow and end up having a negative correlation with the variations in operating cash flow. This negative correlation is a natural result of these accruals. Having a high negative correlation means that the company has used income smoothing.

In this way, the third criterion is a negative correlation between variations in accruals and variations in operating cash flow. 


$$
I A_{3}=\rho\left(\Delta \text { Total Accruals }_{t}, \Delta \text { Operational CashFlow } \text { Act }_{t}\right.
$$

\section{Smoothing metrics}

We use another auxiliary criterion to confirm income smoothing. This criterion is based on linear regression models. Using this, it is possible to determine whether smoothing companies' net income series are less variable than those of non-smoothing ones.

The linear econometric model is:

$$
N I_{i t}=\alpha_{i 1}+\beta_{i 1} t+e_{i t 1}
$$

where:

$$
\begin{aligned}
& \mathrm{NI}_{\mathrm{it}} \text { : Net income of the company in year } t \\
& t \text { : period } t=1,2, \ldots \ldots . .53 \text {. }
\end{aligned}
$$

It can be shown that the degree of income smoothing for smoothers is reflected by a higher $\mathrm{R}^{2}$ or a smaller Akaike-Schwartz coefficient. This happens because the quarterly data on net income of smoothing firms are less variable than those of non-smoothing ones. Hence, the adjustment curves would be explained by data from companies that have less variability in net income. This model is used as auxiliary criterion to test the hypothesis, although it should be recognized that there may be a specification error. Nevertheless, it is believed that this does not invalidate the results expected to be proved.

\section{Metrics for abnormal returns}

We assume that the information on income smoothing is delivered to the market regularly and prices are adjusted progressively to that information. This affords us a correct picture of how the market values the practice of income smoothing, so we perform a long-term association analysis, very similar to that of Michelson et al. $(1995,2001)$.

In this type of long-term analysis, the mathematical criteria selected and the abnormal returns methodology are very important because long-run results are very sensitive.

We consider annual earnings for the analysis of abnormal returns for each asset. We use the Ibovespa (Bovespa index) of Brazilian stocks (1998-2007) to measure market profitability. Abnormal returns (AR) are defined as:

$$
A R_{i t}=R_{i t}-R_{m}
$$

where:

$\mathrm{AR}_{\mathrm{i}, \mathrm{t}}$ : abnormal return of asset $i$ in year $t$

$\mathrm{R}_{\mathrm{i}, \mathrm{t}}$ : return of asset $i$ in year $t$

$\mathrm{R}_{\mathrm{m}}$ : return of the market portfolio in year $t$

To calculate abnormal returns, an assumption on the definition of abnormal returns has to be made. There are many opinions on this subject. In this work, we use the market return variable as a benchmark to calculate abnormal returns, which is very similar of what is recommended by Campbell, Lo and MacKinlay (1997, p. 156). 
To estimate the beta of each asset, we performed the market model in many regressions for the past 36 periods until month $\mathrm{t}$. In this month $\mathrm{t}$, the abnormal return of each asset is calculated as follows:

$$
R_{i t}=\alpha+\beta \times R_{m t}+\varepsilon_{i t}
$$

where: $\beta$ : Systematic risk of asset $i$ in the period $[t-\mathrm{T}, t-1]$.

This market model is a statistical model which relates the return of any given security to the return of the market portfolio. The model's linear specification follows from the assumed joint normality of asset returns. Based on these returns, the objective of this study is to see whether or not the Brazilian market is efficient in gathering information on smoothing.

The analysis of cross-section returns made previously has to be interpreted with care due to possible bias, as stated by Michelson et al. (2001) and Bin et al. (2000). We use the time series method employed by Bao and Bao (2004) and Iñiguez and Poveda (2004) to increase the knowledge of abnormal returns (smoothing and non-smoothing companies). In this case, the procedure identifies unbiased monthly portfolios in which the abnormal monthly return is calculated. This is done by calculating the average abnormal return of each asset and repeating this for each month during the whole time period, with $\tau$ observations ( $\tau=60$ months):

$$
A R_{t}^{p}=\frac{1}{N_{p}} \sum_{j \in S_{p}} A R_{j t} \quad, \text { for } t=1, \ldots \tau
$$

where,

$$
S=1,2, \ldots, N \text {, and, } S_{p} \subset S \text { subset of the sample. } N_{p}=\#\{\mathrm{Sp}\} \leq N
$$

$A R_{j, t}$ is the abnormal return of asset $j$ in month $t, t$ is the number of months in the sample, $p$ shows the number of portfolios and $N_{p}$ is the number of stocks that make portfolio $p$.

We use the significance of each portfolio's average monthly abnormal return to indicate the existence of abnormal returns. The equations below show the average as well as the formula to analyze whether the average is substantially different from zero:

$$
\begin{aligned}
& M M A R_{p}=\frac{1}{\tau} \sum_{j=1}^{\tau} A R_{t}^{p} \\
& t^{*}=\frac{M M A R_{p}}{\sigma\left(A R_{t}^{p}\right) / \sqrt{v}} \sim t \text { student }(v-1)
\end{aligned}
$$

where $\mathrm{AR}_{t}^{p}$ is the abnormal return of portfolio $p$ in month $t, M M A R_{p}$ is the monthly mean abnormal return of portfolio $p$, and $t$ is the number of months of the study period. With the previous procedure, a time series is adjusted by the returns for each level of risk.

To check whether Jensen's alphas are substantially different from zero and contrast different risk levels between portfolios, we use another contrast in time series, based on CAPM estimations. To do this, we measure the return of each portfolio as the average return. This procedure results in returns with $\tau$ observations ( $\tau=60$ months):

$$
R=\frac{\sum_{j=1}^{n=p} R_{j, t}}{N_{p}} \rightarrow t=1,2, \ldots ., \tau
$$


where, $R_{j, t}$ is the abnormal return of asset $j$ in month $t$, $\tau$ is the number of months in the sample, $p$ shows the number of portfolios and $N_{p}$ is the number of stocks that make up portfolio $p$.

Once the time series return of each portfolio has been obtained, then the adjusted abnormal return is obtained. This return is adjusted by risk through Jensen's alpha. This facilitates noting the differences in risk from each portfolio:

$$
R_{i, t}-r_{f t}=\alpha_{i}+\left(R_{m t}-r_{f t}\right) \times \beta+\mu
$$

Additionally, to analyze an arbitrage portfolio we estimate the following regression:

$$
R_{1, t}-r_{4 t}=\alpha_{1}+\left(R_{m t}-r_{f t}\right) \times \beta_{A}+\mu_{A t}
$$

where

$\mu$ and $\mu_{\mathrm{At}}$ are errors in the models

$\alpha_{1}$ and $\beta_{1}$ are parameters for smoothing portfolio

$\alpha_{4}$ and $\beta_{4}$ are parameters for non-smoothing portfolio

This regression basically applies equation (14) to the first smoothing group and the second nonsmoothing group, and then calculates the difference between these two values. As a result, returns from the smoothing group are significantly higher than those of the non-smoothing group.

In model (15), the coefficient $\alpha_{\mathrm{A}}$ is the excess return adjusted by risk for the smoothing portfolio versus the non-smoothing portfolio; $\alpha_{A}=\alpha_{1}-\alpha_{4}$. A positive and significant coefficient indicates excess return from smoothing companies versus the non-smoothing ones. The coefficient $\beta_{\mathrm{A}}$ measures differences in risk from both portfolios; $\beta_{\mathrm{A}}=\beta_{1}-\beta_{4}$. By contrasting the meaning of this coefficient, it can be inferred whether differences in systematic risk are present for smoothing and non-smoothing companies.

\section{Factors that explain income smoothing}

We apply a logistic regression to provide a stronger basis for the results obtained. The idea is to classify a group of companies that engage in smoothing and another group of those that do not, based on risk and return parameters and control variables. The variables used are: (a) Stock volatility; (b) Size (net revenue); (c) Abnormal return; and iv) Beta.

The advantage of the logarithmic (logistic) regression is that it allows a multivariate perspective to be incorporated into the study. This new perspective includes other control variables that can affect the result. In logarithmic regression models, the dependent variable is usually a dummy and the independent variables can be categorical or continuous. Here we classify the observations into one of two mutually exclusive categories $(1$ or 0$)$. Therefore, the categories contain smoothing and non-smoothing companies. The dependent dummy variable $(\mathrm{Y})$ has the following values:

. 1 if the company smoothes income

. 0 if the company does not smooth

We employ two forward stepwise models to determine which variables are more efficient in classifying companies as smoothers or non-smoothers. In both methods selected, the reference for calculation is the probability function of obtaining the results of the entire sample, given the estimation for the parameters of the logistic model. Since this probability is a value less than 1 (one), the expression 2LL is commonly used. Therefore, $2 \mathrm{LL}$ is a measure of the quality of fit of the estimated model applied to the data. The lower $2 \mathrm{LL}$ is, the better the fit. 


\section{Main Empirical Results}

\section{Cross-section for income smoothing, risk and abnormal return}

In the segregation of groups, we found that in general our hypothesis is confirmed. The results in Table 1 show that the average betas of the group companies that smooth was significantly lower than those of the group of non-smoothers ( 0.583 versus 0.913$)$.

Table 1

\section{Descriptive Statistics}

\begin{tabular}{|c|c|c|c|c|c|c|}
\hline Type & & $\mathrm{N}$ & Min & Max & Mean & StanDev \\
\hline \multirow{3}{*}{ Smoothers } & $\beta$ & 64 & 0,1 & 1,5 & 0,583 & 0,37 \\
\hline & AR \% & 64 & $-98,5$ & 921,9 & 253,1 & 202,64 \\
\hline & AMAR\% & 64 & $-2,1$ & 27,17 & 9,69 & 8,9 \\
\hline \multirow{3}{*}{ Non Smoothers } & $\beta$ & 83 & $-0,2$ & 2,9 & 1,195 & 0,449 \\
\hline & $\mathrm{AR} \%$ & 83 & $-222,3$ & 448,1 & 136,4 & 222,07 \\
\hline & AMAR \% & 83 & $-18,64$ & 22,09 & 5,36 & 13,34 \\
\hline
\end{tabular}

Note. Variables: $\beta$ : Beta; AR: Abnormal Return; AMAR: Annual Mean Abnorma Return. Sources: Research data.

For returns, the results show that the annualized market-adjusted abnormal return of smoothers was significantly higher than those of non-smoothers (9.69\% versus only $5.83 \%)$.

The differences in the means of these groups was confirmed by parametric and nonparametric tests, indicating there is a statistically significant difference in performance in the Brazilian market between companies that smooth and those that do not. Smoothers have systematic measures to lower risk and higher return. The results are documented in Table 2 below:

Table 2

Parametric and Nonparametric Results

\begin{tabular}{ccccccccccc}
\hline & \multicolumn{3}{c}{ T Test } \\
\cline { 2 - 11 } Variables & $\mathrm{M}_{0}$ & $\mathrm{M}_{1}$ & $\mathrm{t}$ & Sig. (bilat.) & $\mathrm{R}_{0}$ & $\mathrm{R}_{1}$ & Mann-Whitney & Wilcoxon W & $\mathrm{Z}$ & $\begin{array}{c}\text { Sig. } \\
\text { (bilat.) }\end{array}$ \\
\hline AR & 136,4 & 253,1 & 2,848 & 0,025 & & & & & & \\
AMAR & 5,36 & 9,69 & 2,985 & 0,014 & & & & & & \\
$\beta$ & & & & & 118,8 & 101,5 & 5201 & 7671 & $-2,432$ & 0,01 \\
\hline
\end{tabular}

Note. Variables: $\mathrm{M}_{0}$ : Non Smoothers Mean; $\mathrm{M}_{1}$ : Smoothers Mean; $\mathrm{R}_{0}$ : average ranking of non smoothers; $\mathrm{R}_{1}$ : average ranking of smoothers. Sources: Research data.

Proof of the statistical significance of the difference in average returns between the two groups would show that a share trading strategy of taking a long position in smoothers and short in nonsmoothers would be profitable, ensuring a statistically significant abnormal return. 


\section{Time series for alpha, abnormal return and systematic risk}

In this section we analyze the monthly average returns of portfolios that were formed based on IA1 and IA2. Table 3 summarizes the results of this analysis in time series. The first two columns of Table 3 show that the average monthly abnormal return of the first two portfolios is positive, but for the last two it is negative. Portfolio 1, with a smoothing index of 0.1250 , shows clear evidence of smoothing behavior and has the highest average abnormal return of all portfolios. If an investor had followed a consistent investment strategy of buying Portfolio 1 at the beginning of each month, he would have achieved on average a return of $0.41 \%$ a month after discounting for risk. In contrast, applying this investment strategy to Portfolio 4 would result in an average return of minus $0.53 \%$ discounting for risk. The p-values of both portfolios are below 5\%, so the null hypothesis is rejected that the returns are zero. Finally, if an investor followed a consistent arbitrage strategy of buying the first portfolio and short selling the second, he would obtain on average an excess return of $0.69 \%$ per month, with a p-value less than $5 \%$, allowing rejection of the null hypothesis that the return is zero with that level of significance.

Table 3

\section{Test Result in Time Series}

\begin{tabular}{cccccccccc}
\hline & MMAR & $\mathbf{p}$-value & alfa & $\mathbf{p}$-value a & beta & p-value b & $\mathbf{R}^{2}$ & $\mathbf{N}$ & IS \\
\hline Portfolio 1 & 0,0041 & 0,0031 & 0,0037 & 0,0001 & 0,65 & 0,0000 & 0,92 & 60 & 0,1250 \\
Portfolio 2 & 0,0034 & 0,0086 & 0,0035 & 0,0042 & 1,10 & 0,0000 & 0,93 & 60 & 0,8124 \\
Portfolio 3 & $-0,0040$ & 0,1021 & $-0,0041$ & 0,1124 & 1,39 & 0,0000 & 0,87 & 60 & 1,9451 \\
Portfolio 4 & $-0,0053$ & 0,0312 & $-0,0045$ & 0,0048 & 1,89 & 0,0000 & 0,91 & 60 & 12,2564 \\
& & & & & & & & & \\
Arbitrage Portfolio & 0,0069 & 0,0261 & 0,0072 & 0,0032 & $-1,24$ & 0,0000 & 0,61 & 60 \\
\hline
\end{tabular}

Note. RAMM: abnormal monthly return of each portfolio; p-value: bilateral p-value that MMAA is other than zero; alpha: Jensen's alpha; $\alpha$ p-value: $p$-value adjusted for autocorrelation, heteroskedasticity and the contrast of individual significance of the alpha coefficient; beta: estimated beta; $\beta$ p-value: $p$-value adjusted for heteroskedasticity, autocorrelation and the contrast of individual significance of beta; $\mathrm{R}^{2}$ : coefficient of each regression, $\mathrm{N}$ : number of observations, IS: index of smoothing of each portfolio. Sources: Research data.

Examination of the Jensen alphas of the other columns in Table 3 once again shows the same behavior: higher abnormal returns for the portfolio comprised of companies with clear evidence of smoothing in relation to the last portfolio, in which there is no evidence of smoothing. The first two portfolios on average have positive monthly returns while the last two are losers. Given the contrast of individual significance of the estimated alpha coefficient, Portfolios 1, 2 and 4 indicate rejection of the null hypothesis at 5\%, but this does not occur with the third portfolio, which has a p-value of $11.24 \%$. Regarding the systematic portfolio risk, the estimated betas are significant in all cases and the expected behavior according to the hypotheses specified is borne out. In other words, the first portfolio has a beta of 0.65 , and this measure rises progressively as the smoothing index increases in the other portfolios, to 1.89 in the last portfolio.

The results at the portfolio level are consistent with the cross-section results. The evidence clearly indicates that in the sample analyzed companies with greater evidence of being smoothers, which make up the first and second portfolios, have lower risk levels than firms in the last portfolio, for which there is no evidence of smoothing. The model estimated for the arbitrage portfolio, where beta is interpreted as the differences in risk between the first and fourth portfolio, indicates the differences in risk are significant (beta of negative 1.24, with a significant p-value), with the first portfolio's risk less than that of the last one. 


\section{Income smoothing and firm size}

In this section we analyze whether there is a relation between income smoothing and firm size. Our proxy for size is yearly net operating revenue between 1998 and 2007. With these data we calculated the mean and median of the size of the firms in the sample and carried out two types of analysis based on the smoothing indexes: (a) cross-tabulation analysis of a sample of 244 firms, filtered by the smoothing index $I A_{l}$; and (b) portfolio analysis between size and smoothing, for a sample of 125 firms filtered by the smoothing indexes $I A_{l}$ and $I A_{2}$.

This investigation is particularly relevant to discover whether a firm's size influences its propensity to engage in smoothing. The data are shown in Table 4 and Tables 5 and 6 . The crosstabulation analysis shows a substantially higher number of small firms that are smoothers than expected and a smaller number than expected of large firms.

Table 4

\section{Cross-tabulation: Size vs. Smoothing}

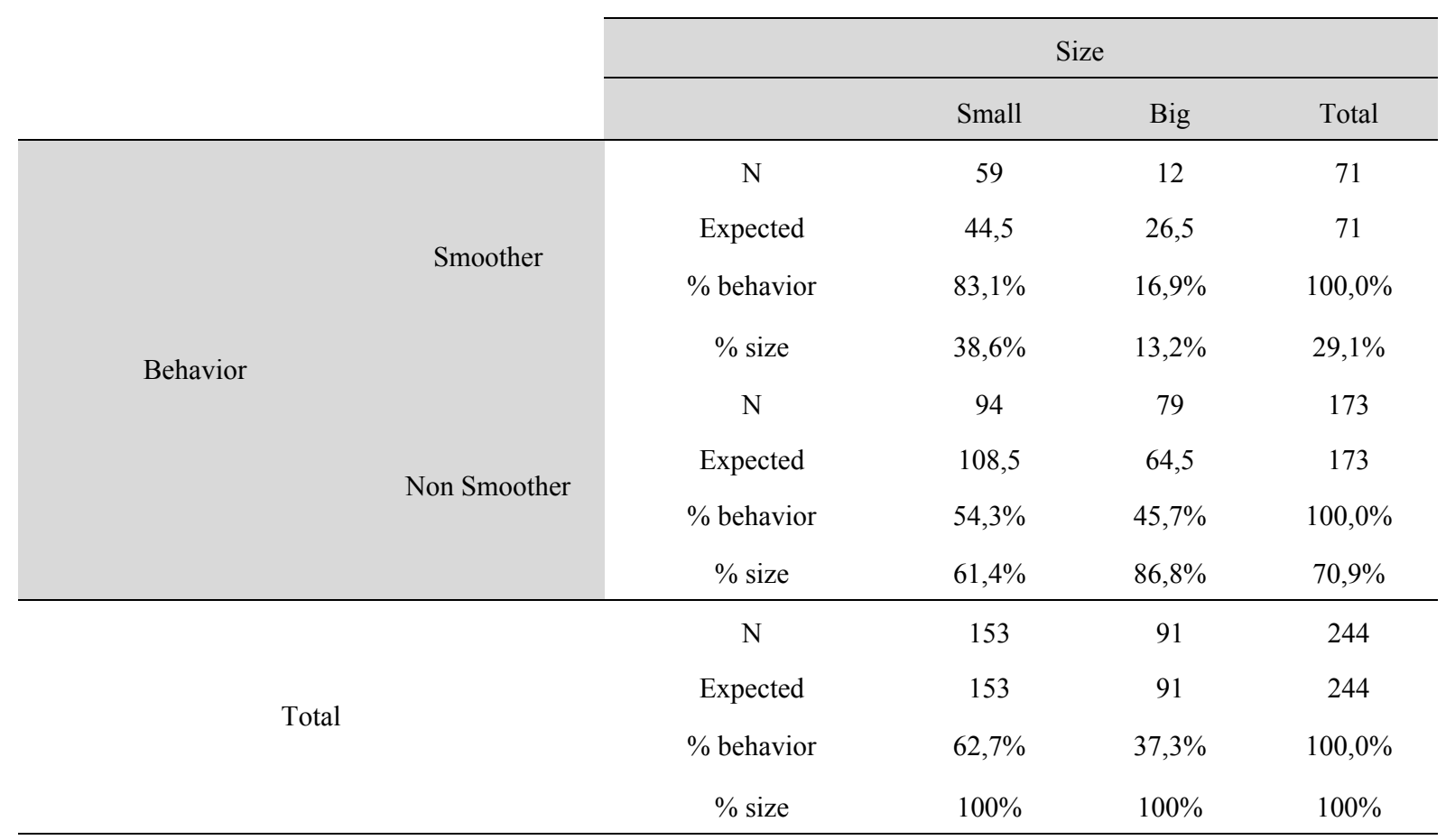

Note. Sources: Research data.

To improve this analysis, we applied the chi-square test and the Wilcoxon test to classify the groups of smoothers by size. This showed that small firms really are more likely to smooth than large ones.

The results of this method are surprising because the evidence is different from the findings for the United States and Europe. This tendency for small Brazilian firms to smooth more frequently led us to formulate a new theoretical assumption to explain this phenomenon.

A plausible explanation is that since small firms face greater risks than large ones, they tend to try to even out the variability of their earnings to offset the risks associated with size.

We also carried out an analysis of a smoothing and non-smoothing portfolio and the relation with firm size. The null hypothesis was that the average net operating revenue in the first portfolio (smoothers) is the same as that for firms in the second portfolio (non-smoothers). The data are shown in Table 6. In this case the null hypothesis was rejected at a p-value of $0.23 \%$. This indicates that the 
size of firms that smooth income is significantly different from that of firms that do not, with smaller ones more likely to do so. To ensure the robustness of this result, since the total assets variable was not normally distributed and there were also some outliers, we utilized the median as a measure of the central position of each group, and once again examined the null hypothesis that the groups are equal. In this case, with the nonparametric Wilcoxon test we obtained a p-value of 3.2\%, corroborating the existence of statistically significant size differences between firms that do and do not smooth earnings.

Table 5

Relation between Smoothing and Size Using the Cross-Tabulation Methodology

\begin{tabular}{llcc}
\hline & Chi-Square Test & & \\
\hline & Value & gl & Sig. Bilateral \\
\hline Pearson Chi-Square & 17,809 & 1 & 0,000 \\
Likelihood Ratio & 19,288 & 1 & 0,000 \\
Fischer Test & & & 0,000 \\
Valid Cases & 244 & & \\
\hline & Wilcoxon Test & & $\mathrm{Z}$ \\
\hline Size - Behavior & & Sig. Bilateral & $-13,54$ \\
\hline
\end{tabular}

Note. Sources: Research data.

Table 6

Relation between Smoothing and Size Using the Portfolio Methodology

\begin{tabular}{ccccc}
\hline & IA & N & AT Mean & AT Median \\
\hline Portfolio 1 & 0,1250 & 28 & 1.045 .432 & 129.786 \\
Portfolio 2 & 0,8124 & 32 & 874.567 & 342.751 \\
Portfolio 3 & 1,9451 & 36 & 483.421 & 438.862 \\
Portfolio 4 & 12,2564 & 29 & 355.891 & 532.876 \\
\hline Test & & 125 & & Wilcoxon \\
\hline Difference P-value test 1;4 & & & $X^{2}$ & 0,0320 \\
\hline
\end{tabular}

Note. Sources: Research data.

Thus, our results on the positive and significant relation between size and smoothing, with small firms more likely to do so in Brazil, runs counter to those found by other authors. However, most of these other authors used a different methodology to measure smoothing, such as Moses (1987). He used variations in discretionary accruals to measure smoothing and found that large firms smooth income more often than small ones. The results here, then, are surprising because they present evidence unlike that found in the United States and France. 
The fact that we reached similar conclusions through different methodologies strongly indicates that smaller firms are more likely to smooth in the Brazilian market. Again, this can be explained by the risk perception associated with size: smaller firms are seen as riskier, so they feel a greater need to smooth their earnings in an attempt to offset the risks associated with size.

\section{Factors that explain income smoothing}

To obtain more robust results, we carried out a logistic regression, seeking to classify the smoothing group based on risk and return parameters along with some control variables. Once again the results confirmed the findings in the previous analyses.

We used the following control variables to explain the classification of firms as smoothers and non-smoothers: (a) volatility; (b) size (gross revenue); (c) abnormal return; and (d) beta. In the process of improving the model we kept the most statistically relevant statistics in the regression.

Table 7 shows the results. It can be seen that volatility and size are explanatory variables, as found in the previous analyses. The advantage of logistic (or logarithmic) regression is that it permits including a multivariate perspective in the study, including consideration of other control variables that could affect the result.

Table 7

\section{Logistic Regression Results}

\begin{tabular}{|c|c|c|c|c|c|c|c|c|}
\hline \multirow{2}{*}{\multicolumn{2}{|c|}{$\frac{(*)-2 \text { Long Likelihood }}{198.232}$}} & P-value & \multicolumn{3}{|c|}{ Cox \& Snell R Square } & \multicolumn{3}{|c|}{ Nagelkerke T Square } \\
\hline & & 5.324 & \multicolumn{3}{|c|}{0.687} & \multicolumn{3}{|c|}{0.745} \\
\hline \multicolumn{3}{|c|}{ Hosmer and Lameshow Test } & \multicolumn{4}{|c|}{ Omnibus Test of model Coeficients } & \multicolumn{2}{|c|}{ Predicted } \\
\hline Qui ${ }^{2}$ & df & Sig. & & Qui ${ }^{2}$ & df & Sig. & $\mathbf{0}$ & 1 \\
\hline 15.093 & 8 & 0.097 & Model & 96.046 & 2 & 0.000 & $94.20 \%$ & $63.40 \%$ \\
\hline
\end{tabular}

Variable: Non smoother: 0; Smoother: 1

\begin{tabular}{cccccccccc}
\hline & & & & & & & \multicolumn{2}{c}{$95,0 \%$ C.I.for EXP(B) } \\
\cline { 6 - 10 } & B & S.E. & Wald & df & Sig. & Exp(B) & Lower & Upper \\
\hline Volatility & -0.054 & 0.009 & 33.477 & 1 & 0.000 & 0.947 & 0.93 & 0.965 \\
Size & -1.376 & 0.229 & 36.125 & 1 & 0.000 & 0.253 & 0.596 & 0.712 \\
Constant & 9.321 & 1.432 & 42.396 & 1 & 0.000 & 11173.353 & & & \\
\hline
\end{tabular}

Note. Sources: Research data.

The first column of indicators in Table 7 presents the -2LL statistic, which can be used to evaluate the quality of the fit, the p-value of 5.324 shows that the null hypothesis cannot be rejected that the model fits the data. This column also presents the pseudo- $\mathrm{R}^{2}$ values of Cox \& Snell $(0.687)$ and Nagelkerke (0.745). These values reveal the model has adequate quality to explain the dependent variable.

The next indicator column shows the Hosmer and Lemeshow goodness of fit values and the observed and expected values used to calculate the test statistic $\left(\chi_{(8)}^{2}=15.093\right.$, p-value $\left.=0.097\right)$. This indicates that the values estimated by the model are near those observed, implying the model fits the data.

The next column presents the omnibus test of model coefficients between the null model and final model, with a p-value $<0.05$. This indicates that at least one independent variable in the final model has predictive power over our independent variable (smoothing behavior). It can be observed 
under Predicted that the test has predictive capacity of $94.20 \%$ for non-smoothing behavior and $63.40 \%$ for smoothing behavior. The final part of Table 7 summarizes the information on the independent variables of the complete model. According to the Wald test and p-value associated with them, the two variables that explain the smoothing behavior (size and volatility) are significant at the $5 \%$ level.

\section{Final Considerations}

The economic and financial press regularly comments on the accounting manipulations of managers to modify their firms' published results. In this respect, income smoothing has attracted substantial attention in the literature. There are many studies in the international literature that indicate that firms engage in practices to reduce the variance of earnings. This paper adds to this evidence, showing empirically that Brazilian public companies engage in smoothing, i.e., they take advantage of the inherent leeway in accounting rules to artificially smooth out their earnings.

Based on the analysis of a sample of firms over the period from 1998 to 2007, this paper presents empirical evidence that Brazilian companies that engage in smoothing on average stand apart from those that do not with respect to risk, return, size and industrial sector.

The results can be summarized by the hypotheses investigated, as follows in Table 8:

Table 8

\section{Results of the Study}

$\begin{array}{cl}\text { Hypothesis } 1 & \begin{array}{l}\text { The analyses show that firms classified as smoothers have a significantly lower beta than } \\ \text { non-smoothers. }\end{array} \\ \text { Smoothing and Risk } & \text { These results were supported both by univariate and multivariate analyses. } \\ \text { The analyses show that in average terms the smoothing companies had a significantly } \\ \text { hypothesis } 2 & \begin{array}{l}\text { higher abnormal annual return than the non-smoothers. } \\ \text { The results support the utilization of a portfolio strategy of assuming a short position in } \\ \text { non-smoothing companies and a long position in smoothers. }\end{array} \\ \text { Hypothesis } 3 & \begin{array}{l}\text { The size of companies plays a role in motivating managers to engage in smoothing. Small } \\ \text { firms have a greater propensity to smooth income than large ones. }\end{array} \\ \text { The results were produced by a univariate analysis supported by the chi-square and } & \text { Wilcoxon tests. }\end{array}$

The results of this study are particularly important for risk-averse investors who wish to obtain higher returns by structuring their portfolios. The results indicate that strategies can be formulated from classifying firms as smoothers and non-smoothers because the sample portfolios formed of companies showing smoothing behavior in all cases obtained better returns than those formed of nonsmoothing firms. We detected a progressive decline in the adjusted returns for each risk level, from positive in the first portfolio to negative in the last one. In all the returns calculated with the corresponding risk adjustment, as well as alternative adjustments, as in the case of the market portfolio, in all cases there was sufficient evidence to consider the results significant and robust in light of the multiple refinements proposed in the comparison of abnormal returns

With respect to the systematic risk of the stocks, both on an individual basis and at the portfolio level, we detected that the risk declines with the degree of smoothing by firms, with the riskiest ones being those that did not show any evidence of smoothing behavior and the risk significantly lower in firms engaging in smoothing. 
However, our results should be interpreted with care given some underlying limitations of the sample and methods employed, leading to suggestions for more comprehensive and complex future studies on the theme. A possible extension would be to include firms from several different countries. Besides allowing for more robust statistical tests, this would permit extending the time frame and making broader comparative analyses of income smoothing (determining whether this practice exists in the same intensity and for the same reasons in different countries). From a methodological standpoint, it would be interesting in future studies to identify smoothing practices in Brazil by employing other methods that have been reported in the literature, such as by specifying time-series econometric models.

The questions addressed here can also be developed further in various ways. Among the points for future research are: How does the practice of income smoothing dynamically affect firm value? How can the difference in abnormal returns between smoothers and non-smoothers be explained? A critical point of any study is the definition of alternative metrics for classifying companies. Another interesting extension would be to examine the relationship between smoothing and the cost of equity capital.

Among the main implications of this study, perhaps the main one is that financial managers can find scientific evidence here justifying earnings management with positive effects (beneficial smoothing). From this perspective, the practice of managing earnings to reduce variability could be beneficial by reducing possible distortions in stock prices. Smoothing signals value to the market to the extent it reduces systematic risk and constitutes an unquestionable guide to value. Since the objective function of management is to increase the firm's value, and since managers have a certain degree of discretion to manage accounting numbers, smoothing out earnings can generate value for shareholders.

However, a caveat is in order here. Since less variability in the series of reported earnings can boost the value of the firm, this can lead to abusive smoothing, where in a market with asymmetric information, the pooling equilibrium in signaling, in the context of game theory, prompts managers to engage in pernicious smoothing to mimic firms with genuinely smooth earnings series. In such a context, it is important to have regulatory instruments to discourage the abusive manipulation of the risk perception of investors.

\section{Received 19 October 2009; received in revised form 25 May 2010.}

\section{References}

Albrecht, W. D., \& Richardson, F. M. (1990). Income smoothing by economy sector. Journal of Business Finance and Accounting, 17(5), 713-730. doi: 10.1111/j.1468-5957.1990.tb00569.x

Archibald, T. R. (1967). The return to straight-line depreciation: an analysis of a change in accounting method. Journal of Accounting Research, 5(3), 164-180.

Ashari, N., Koh, H. C., Tan, S. L., \& Wong, W. H. (1994). Factors affecting income smoothing among listed companies in Singapore. Accounting and Business Research, 24(96), 291-301.

Bao, B. H., \& Bao, D. H. (2004). Income smoothing, earnings quality and firm valuation. Journal of Business Finance and Accounting, 31(9-10), 1525-1557. doi: 10.1111/j.0306686X.2004.00583.x

Bhat, V. N. (1996). Banks and income smoothing: an empirical analysis. Applied Financial Economics, 6(6), 505-510. doi: 10.1080/096031096333953 
Bin, K. W., \& Kamil, K. (2000). Market perception of income smoothing practices: Malaysian evidence. Journal of Economics and Finance, 26(2), 132-146.

Booth, G. G., Kallunki, J. P., \& Martikainen, T. (1996). Post-announcement drift and income smoothing: finnish evidence. Journal of Business Finance and Accounting, 23(8), 1197-1211. doi: $10.1111 / j .1468-5957.1996 . t b 01165 . x$

Campbell, J. Y., Lo, A. W., \& MacKinlay, A. C. (1997). The econometric of financial markets. New Jersey: Princeton University Press.

Carlson, S. J., \& Bathala, C. T. (1997). Ownership differences and firms' income smoothing behaviour. Journal of Business Finance and Accounting, 24(2), 179-196. doi: 10.1111/14685957.00101

Chalayer, S. (1994). Identification et motivations des pratiques de lissage dês résultats comptables des entreprises françaises cotées en Bourse. Ph.D. dissertation, Saint-Etienne University, SaintEtienne, France.

Chaney, P. K., \& Lewis, C. M. (1995). Earnings management and firm valuation under asymmetric information. Journal of Corporate Finance, 1(3-4) 319-345.

Copeland, R. M. (1968). Income smoothing. Journal of Accounting Research, 6(Suppl.), 101-116.

Craig, R., \& Walsh, P. (1989). Adjustments for 'extraordinary items' in smoothing reported profits of listed Australian companies: some empirical evidence. Journal of Business Finance and Accounting, 16(2), 229-245. doi: 10.1111/j.1468-5957.1989.tb00015.x

Eckel, N. (1981). The income smoothing hypothesis revisited. Abacus, 17(1), 28-40. doi: $10.1111 / \mathrm{j} .1467-6281.1981 . t b 00099 . x$

Gordon, M. J. (1964). Postulates, principles and research in accounting. The Accounting Review, $39(2), 251-263$.

Grant, J., Markarian, G., \& Parbonetti, A. (2007). CEO risk-related incentives and income smoothing. Retrieved October 19, 2009, from http://SSRN.com/abstract $=975266$

Iñiguez, R., \& Poveda, F. (2004). Long-run abnormal returns and income smoothing in the Spanish stock market. European Accounting Review, 13(1), 105-130. doi: $10.1080 / 0963818032000138224$

Leuz, C., Nanda, D., \& Wysocki, P. (2003). Earnings management and investor protection: an international comparison. Journal of Financial Economics, 69(3), 505-527.

Lev, B., \& Kunitzky, S. (1974). On the association between smoothing measures and the risk of common stocks. The Accounting Review, 49(2), 259-270.

Michelson, S. E., Jordan-Wagner, J., \& Wootton, C. W. (1995). A market based analysis of income smoothing. Journal of Business Finance and Accounting, 22(8), 1179-1193. doi: $10.1111 / \mathrm{j} .1468-5957.1995 . t b 00900 . x$

Michelson, S. E., Jordan-Wagner, J., \& Wootton, C. W. (1999). The relationship between the smoothing of reported income and risk-adjusted returns. Journal of Economics and Finance, 24(2), 141-159.

Michelson, S. E., Jordan-Wagner, J., \& Wooton, C. W. (2001). Accounting income smoothing and stockholder wealth. Journal of Applied Business Research, 10(3), 96-110. 
Moses, O. D. (1987). Income smoothing and incentives: empirical tests using accounting changes. The Accounting Review, 62(2), 358-377.

Ronen, J., \& Sadan, S. (1981). Smoothing income numbers: objectives, means, and implications. Massachusetts: Addison-Wesley Publishing Company, Reading.

Ronen, J., \& Yaari, V. (2007). Legal insider trading, CEO's incentive, and quality of earnings. Corporate Governance and Control, 4(2), 210-219.

Tan, H.-C., \& Jamal, K. (2006). Effects of accounting discretion on ability of managers to smooth earnings. Journal of Accounting and Public Policy, 25(5), 554-573.

Trueman, B., \& Titman, S. (1988). An explanation for accounting income smoothing. Journal of Accounting Research, 26(Suppl.), 127-139.

Tucker, J., \& Zarowin, P. (2006). Does income smoothing improve earnings informativeness? The Accounting Review, 86(1), 251. doi: 10.2308/accr.2006.81.1.251

Watts, R., \& Zimmerman, J. (1986). Positive accounting theory. Englewood Cliffs, N.J.: Prentice-Hall Inc.

White, G. (1970). Discretionary accounting decisions and income normalization. Journal of Accounting Research, 8(2), 260-274. 